\title{
Virtual project as a tool for leadership skills development
}

\author{
Aleksandra Kobicheva ${ }^{1 *}$ \\ ${ }^{1}$ Peter the Great St. Petersburg Polytechnic University, Polytechnicheskaya, 29, Saint-Petersburg, \\ Russia
}

\begin{abstract}
The paper is dedicated to the investigation of international online project influence on students' leadership skills development. The sample included 141 students who participated in the online X-culture project as a part of their professional discipline course. The research was carried out in the years 2019-2020. The students were surveyed every week during a 2-month length project. For the analysis, we used the answers of the first and the last surveys to determine the impact of the project. The results showed significant improvements in all indicators of Leadership skills that confirmed the positive influence of the X-culture project. Moreover, we conducted inter-views with ten random students to reveal the influencing factors of the project and define whether the project changes students' behavior toward professional discipline learning. Students confirmed the positive influence of working in a virtual team on their communication skills and general motivation to study the professional discipline. Thus, we confirmed the importance of implementing project activity into the courses of professional discipline due to substantial influence on leadership skills development and higher engagement in the learning process.
\end{abstract}

\section{Introduction}

The dynamic development and changes in many spheres of life in Russian society have led to changes in the education system. Today it is not enough for a modern graduate just to possess a certain amount of knowledge, skills and abilities, he needs to be able to apply them in practice independently and creatively. That is, the state, through the introduction of federal state educational standards of a new model, seeks to obtain a highly qualified specialist who possesses the necessary knowledge, who is ready to apply it in any, including a non-standard situation [1].

Modern society needs competent and active specialists who are able to independently solve production problems, who are ready to take responsibility for their implementation, who are able to clearly define the goals of their activities, predict options for achieving them, overcome difficulties, work in a team, that is, show leadership [2, 3]. Now the task of higher professional education is to create conditions for students to show creative initiative, for maximum immersion of students in future professional activities. Such training will

* Corresponding author: kobicheva92@gmail.com 
contribute to the development of ap-propriate skills and fastest adaptation of students to the real professional field after graduation. Modern education operates on the basis of a competence-based approach, because it is thanks to it that the necessary conditions, indicated by us above, are created.

One of the best ways to implement the competence-based approach is project activity, which gives students freedom of thought and creativity and allows them to prepare the student for future professional conditions as much as possible [3]. In this case, the international virtual project X-culture was introduced in curricular of professional discipline at Peter the Great Polytechnic university. The duration of the project was 10 weeks, during which students actively implemented various business cases in international teams. The communication between team members was to-tally online.

The aim of the current study is to assess the influence of virtual project activity on the leadership skills development.

\section{Background}

\subsection{Online project X-Culture}

Working as a team on one project requires many skills [4]. In our re-search, we consider an international online project for students. But first of all, it is worth clarifying the concept of project management. According to Knutzon and Bitz, project management is "a set of principles, methods, tools, and techniques for the effective management of objectiveoriented work in the context of a specific and unique organizational environment." [5]. Kerzner emphasized project management as "the art of creating the illusion that any outcome is the result of a series of predetermined, deliberate acts when in fact it was dumb luck." [6]. Havranek expanded on Kerzner's definition. He defined project management as "project management is the art and science of planning, organizing, integrating, directing, and controlling all committed resources - through-out the life of a project - to achieve the predetermined objectives of scope, quality, time, cost, and customer satisfaction" [7].

The article by Taras et al. [8] focuses on the experimental component of international business education. An article written by 11 authors from the USA, Poland, Ecuador, Spain and the United Arab Emirates de-scribes an exciting new collaborative consulting project called X Culture. Using state-of-the-art technology, social media and online collaboration tools, students from different schools and countries are challenged to develop real-world consulting projects. The article discusses many of the positive outcomes of students and presents opportunities for other inter-national business teachers.

Another study related to the X-Culture project [9] explores the problems and experiences of X-Culture through the eyes of professors and students and draws attention to the importance of such projects in inter-national business practice, in addition to examining the key factors influencing interculturalism and ICT technologies. The researchers found that many students increased their chances of finding attractive jobs in the labor market and broadened their social and professional ties by participating in the X-Culture International Student Cooperation Project. The problems were mainly related to differences in time, but cultural differences and language barriers often emerged.

\subsection{Leadership skills}

One of the numerous approaches to leadership is an approach based on the skills or the knowledge and skills that leaders should possess. Over years, researchers have addressed the question of what skills leaders need to possess (Bass, 1990). Approach to leadership 
from the standpoint of skills started with the article of Robert Katz, entitled "Skills of an Effective Administrator", which was published in 1955, in Harvard Business Review. The standpoint of skills was meant to overcome the standpoint of properties, according to which the concept of the capacities for leadership depends on the personality traits which are inherited. (Northousse, 2010). The stand-point of skills makes possible leadership to be taught. Katz claimed that leaders can acquire and develop skills, while personality traits are something we are born with (Katz, 1955). Katz has proposed three groups of skills: technical, interpersonal and abstract thinking skills. Technical skills are related to knowledge and expertise on a particular line of business. Interpersonal skills refer to the skills and ability to work with people, and abstract thinking skills relate to the ability to work with ideas.

Leadership skills are the tools, behaviors and capabilities that leaders should have in promoting well-being of the employees and leading to up-gradation of the organizations. The primary job duties of the leaders are focused towards directing and motivating employees towards the implementation of job duties and achievement of goals and objectives. The true leadership skills involve helping the individuals grow in their own abilities.

Chobharkar (2011) has made an attempt to make a list of leadership qualities and skills that identifies all the necessary character traits of a good leader [10]. According to him, there are 5 "basic" qualities and skills: relationships, team building, vision and strategy, decision making, and planning. However, the author argues that this list contains only the most prominent leadership attributes; there are many more skills that a leader may need but the ones identified by him are mandatory.

On the other hand, Chobharkar stated that each of the 5 skills is closely linked with other skills. In fact, the successful use of a skill in a specific situation requires the use of several other skills that are related to the 5 basic leadership skills and those related to each of them can be grouped in Figure 1 that shows the interference between the leadership skills.

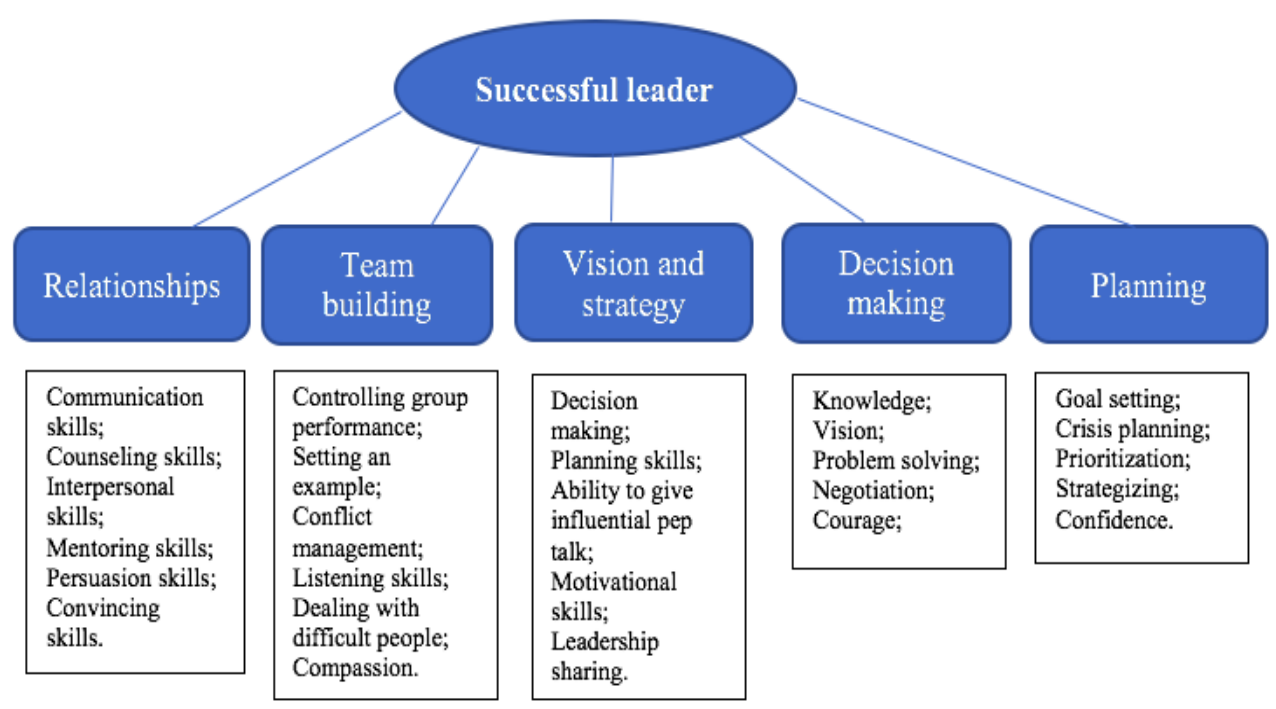

Fig. 1. Leadership skills composition.

The above-mentioned model of leadership skills constitutes the methodological basis of our research that is presented further. 


\section{Materials and methods}

For our research we used the data of X-culture online surveys. The re-search is based on the analysis of data collected during the fall semesters of 2019 and spring semester 2020. In these periods eight groups of 4th year bachelors took part in an intercultural online project X-culture as a part of the course "International Business" (the sample included 141 students). From the demographic point of view, 96\% of respondents were in 20-22 age group and $66 \%$ were female. In order to evaluate the influence of X-culture project and intercultural communication in virtual teams on students' leadership skills we conducted two online questionnaire-based surveys before the project and after the project. The evaluation of leadership skills was based on Chobharkar model that defines 5 leader-ship qualities and skills: Relationships (R), Team building (TB), Vision and strategy (VS), Decision making (DM) and Planning (P). Concerning the reliability of the leadership skills scale, the total Cronbach's alpha was 0.718 . The results for each dimension in part were as follows: R (0.721), TB (0.733), VS (0.761), DM (0,727), P (0,704). All indicators are higher or close to the 0.7 threshold value that can be considered as good or at least acceptable.

Also, we conducted several interviews with random students after the project.

For the analysis descriptive statistics, pair-samples Students' t-test and Pearson correlation test were conducted.

\section{Results}

\subsection{Students' survey results}

The survey included 27 questions (to evaluate the development of each skill and personal qualities that constitute leadership skills). Students gave answers on a 10-point Likert scale, so it was possible to determine whether the X-culture virtual project had an impact on leadership skills development.

Table 1. Results of t-test.

\begin{tabular}{|c|c|c|c|c|}
\hline Skills & Survey & Mean & SD & $\mathrm{t}$-value \\
\hline \multirow{2}{*}{ Relationships } & Before the project & 6.4 & 0.87 & \multirow{2}{*}{$4.08 * * *$} \\
\hline & After the project & 7.8 & 0.9 & \\
\hline \multirow{2}{*}{ Team building } & Before the project & 6.0 & 0.79 & \multirow{2}{*}{$2.57 * *$} \\
\hline & After the project & 7.02 & 0.81 & \\
\hline \multirow{2}{*}{$\begin{array}{l}\text { Vision and } \\
\text { strategy }\end{array}$} & Before the project & 5.64 & 0.84 & \multirow{2}{*}{$1.98^{*}$} \\
\hline & After the project & 6.12 & 0.82 & \\
\hline \multirow{2}{*}{$\begin{array}{l}\text { Decision } \\
\text { making }\end{array}$} & Before the project & 6.23 & 0.77 & \multirow{2}{*}{$2.11^{*}$} \\
\hline & After the project & 6.8 & 0.8 & \\
\hline \multirow{2}{*}{ Planning } & Before the project & 5.21 & 0.91 & \multirow{2}{*}{1.49} \\
\hline & After the project & 5.47 & 0.88 & \\
\hline
\end{tabular}

According to the survey results students X-culture project has a positive influence on leadership skills development. It was revealed that students mostly developed relationships skills during participation in X-culture project (the difference in this indicator is significant 
at $\mathrm{p}<0,001)$. Such skills as team building also improved a lot after the project due to students' answers.

\subsection{Students' interview}

We interviewed 10 project participants. The students were selected randomly for the interview. The interview was conducted after the completion of the project, but before the final grades were given, in order to exclude the influence of the received grade on the students answers. The interview was recorded with the consent of the respondents for more detailed review during the analysis. The duration of each interview averaged 40 minutes. The students were asked to answer in detail 8 questions about their experience of participation in the project and the impact of the considered project on the development of collaboration skills.

The students were asked the following questions:

1. Please describe your teamwork. Have you been an active participant?

2. Have there been any conflicts in the team? Did you manage to solve the problems quickly?

3. What emotions did you most often experience during the project?

4. Describe your impressions of working in an international team.

5. How has your participation in the project affected your communication skills? Has it become easier for you to communicate in a group?

6. What skills do you consider to be the most important for a successful collaboration?

7. Do you find your experience in the project useful in developing your leadership skills?

8. Do you find participation in the project useful for studying professional discipline?

After analyzing the students' answers, we found that the students' re-plies can be conditionally divided into 3 groups depending on their participation in teamwork: active participants with leadership qualities, hardworking and executive team players, passive observers (see Fig. 2).

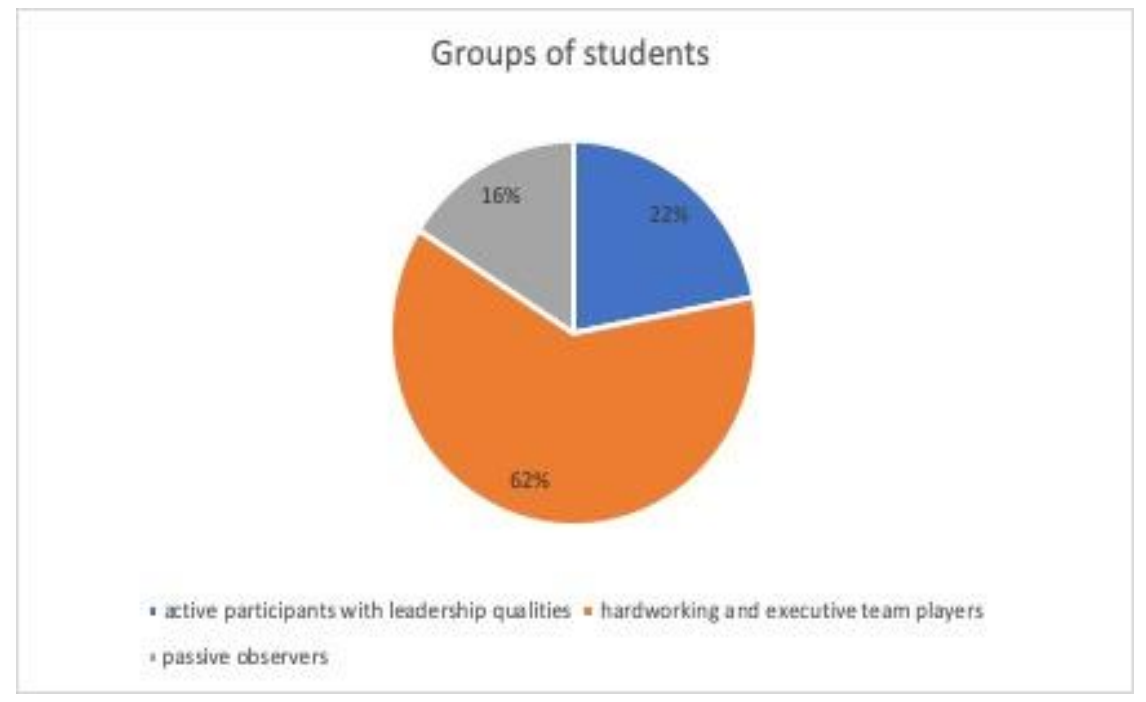

Fig. 2. Leadership skills composition.

\section{Conclusion}


The results of the study show the substantial influence of international online project Xculture on the development of students' leadership skills. In all groups of leadership skills Relationships, Team building, Vision and strategy, Decision making, and Planning students indicated an increase. In this case, we can recommend the project-based learning for leadership skills development, that are crucial for accomplishing the highest scores and efficient task implementation.

The students participating in the interview indicated the effectiveness of involvement in an international online project X-Culture for the development of leadership skills, although they did not assess their experience unambiguously. It can be concluded that those students who have great communication qualities work more effectively in a team and were able to develop stronger their leadership skills. In contrast, less active students experienced communication difficulties during the project, as well as a lack of knowledge of the professional discipline, which reduced their self-confidence. Despite this, this experience was useful for all project participants.

The theoretical work of other scholars in this field has been a useful resource for planning and designing, and we expect that our study will provide something of value for future researchers, too. Of course, there are some limitations in our study, as it does not take into account a novel-ty effect-students did not have an experience of classes that included project activity. Additionally, the sample size was relatively small because it was the second time, we implemented X-culture project in educational curricula.

In our further research we are going to analyze the impact of X-culture international project on cognitive abilities of students.

\section{References}

1. T. Baranova, A. Kobicheva, E. Tokareva, Advances in Intelligent Systems and Computing 1114 (2020)

2. E.B. Volodarskaya, A.S. Grishina, L.I. Pechinskaya, Virtual Learning Environment in Lexical Skills Development for Active Vocabulary Expansion in Non-Language Students Who Learn English. 2019 12th International Conference on Developments in eSystems Engineering (DeSE), Kazan, Russia, pp. 388-392 (2019)

3. T. Baranova, A. Kobicheva, N. Olkhovik, E. Tokareva, Lecture Notes in Networks and Systems, 131 (2020), doi: 10.1007/978-3-030-47415-7_45

4. Y. Dorovskaya, D. Mokhorov, V. Snetkov, K. Semenova, A. Tebryaev, Conference Series: Materials Science and Engineering 940(1), 012044 (2020)

5. J. Knutson, I. Bitz, Project Management: How to Plan and Manage Successful Projects (AMACOM Div. American. Mgmt Assn.,1991)

6. H. Kerzner, Project Management A Systems Approach to Planning, Scheduling, and Controlling (2nd ed.) (Van Nostrand Reinhold, New York, 1984)

7. T.J. Havranek, Modern Project Management Techniques for the Environmental Remediation Industry (CRC Press, 1998)

8. V. Taras, P. Bryla, S. Gupta, A. Jimenez, M. Minor, M. Tim, X. Ordeñana, D. Rottig, R. Sarala, N. Zakaria, S. Zdravkovic, AIB Insights, 12, 11-17 (2012)

9. J. Poór, C. Dr. Kollar, Z. Szira, V. Taras, E. Varga, Journal of Intercultural Management 10, 5-41 (2018), 10.2478/joim-2018-0001

10. P. Chobharkar, Leadership skills List (2011). Retrieved from: http://www.buzzle.com

11. M. A. Osipova, Russian Journal of Criminology 3, 83-88 (2016) 
12. Y. Dorovskaya, D. Mokhorov, V. Snetkov, K. Semenova, A. Tebryaev, The Social Consequences of Innovations in Public Administration IOP Conference Series:

Materials Science and Engineering 940(1), 012044 (2020) 